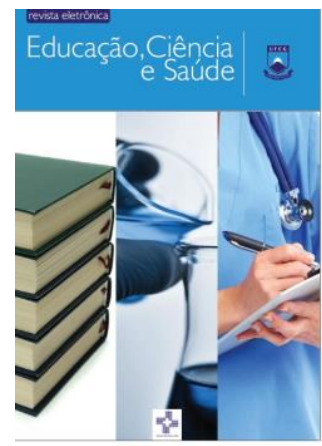

EDUCAÇÃO CIÊNCIA E SAÚDE

http://dx.doi.org/10.20438/ecs.v5i2.153

\title{
AVALIAÇÃO DE PARÂMETROS FÍSICO-QUÍMICOS E EFICÁCIA ANTIMICROBIANA DE SANEANTES DOMISSANITÁRIOS DE ABRANGÊNCIA LOCAL E NACIONAL
}

\author{
Ana Nathália Araújo Andrade ${ }^{1}$, Francisco Patricio de Andrade Júnior ${ }^{1}$, Maria da \\ Glória Batista de Azevedo², Egberto Santos Carmo ${ }^{4}$, Júlia Beatriz Pereira de \\ Souza* 4 \\ ${ }^{1}$ Curso de Bacharelado em Farmácia, Unidade Acadêmica de Saúde, Universidade Federal de \\ Campina Grande, Cuité-PB, Brasil. \\ ${ }^{2}$ Instituto de Pesquisa em Fármacos e Medicamentos, Universidade Federal da Paraíba, João \\ Pessoa-PB, Brasil. \\ ${ }^{3}$ Prof ${ }^{a}$ Unidade Acadêmica de Saúde, Universidade Federal de Campina Grande, Cuité, PB, \\ Brasil. \\ Email para correspondência: juliabtriz@gmail.com
}

\section{Resumo}

No Brasil, a crescente utilização de desinfetantes trouxe uma maior responsabilidade de sua regularização, sendo a Agência Nacional de Vigilância Sanitária responsável pela aprovação e fiscalização destes produtos com o intuito de garantir qualidade e segurança. Diante disso, o presente trabalho teve como objetivo avaliar parâmetros físico-quimicos $(\mathrm{pH}$, índice de espuma e teste de centrífuga) e a eficácia de desinfetantes frente às amostras de Aspergillus niger, Candida albicans, Escherichia coli, Pseudomonas aeruginosa e Staphylococcus aureus. Neste estudo, foram testados dois desinfetantes de abrangência nacional e dois desinfetantes de abrangência local (Ceará e Paraíba). Após a realização dos testes, todos os desinfetantes apresentaram conformidade com o teste de centrífuga e índice de espuma. As amostras $\mathrm{B}, \mathrm{C}$ e $\mathrm{D}$ apresetaram $\mathrm{pH}$ na faixa de crescimento microbiano $(7,6$ a 8,2$)$ e o produto $\mathrm{A}$ apresentou o $\mathrm{pH}$ mais alcalino $(11,5)$, não demonstrando relação com a eficácia antimicromiana. Foi comprovada nenhuma eficiência dos produtos de abrangência local, e os desinfetantes de abrangência nacional não foram capazes de inibir o crescimento de $A$. niger, $C$. albicans e $P$. aeruginosa.

Palavras-chave: saneante, eficácia antimicrobiana, controle de qualidade.

\begin{abstract}
In Brazil, the increasing use of disinfectants has brought greater responsibility for its regularization, and the National Sanitary Surveillance Agency is responsible for approving and supervising these products in order to guarantee quality and safety. The objective of this study was to evaluate the physico-chemical parameters $(\mathrm{pH}$, foam index and centrifuge test) and the efficacy of disinfectants against the samples of Aspergillus niger, Candida albicans, Escherichia coli, Pseudomonas aeruginosa and Staphylococcus aureus. In this study, two disinfectants of national scope and two disinfectants of local scope (Ceará and Paraíba) were tested. After
\end{abstract}


the tests, all disinfectants complied with the centrifuge test and foam index. Tha samples $\mathrm{B}, \mathrm{C}$ and $\mathrm{D}$ showed the $\mathrm{pH}$ in the microbial growth range (7.6 a 8.2), showing no relation with antimicrobial efficay. No efficacy of locally available products was proven, and nationally available disinfectants were not able to inhibit the growth of $A$. niger, $C$. albicans and $P$. aeruginosa.

Keywords: sanitation, antimicrobial efficacy, quality control.

\section{Introdução}

A utilização de desinfetantes ocorre desde os primórdios. Em A Odisseia, Homero cita o uso do enxofre, na sua forma de dióxido de enxofre (aproximadamente 800 a.C.). Essa foi a primeira referência que se conhece sobre desinfecção. Louis Pasteur, em 1864, constatou que os microrganismos causavam as doenças infecciosas, oferecendo importante contribuição ao fortalecimento da Microbiologia. Seu método desenvolvido, conhecido como pasteurização, é utilizado até os dias atuais na higienização de alimentos. A utilização de produtos antissépticos vem bem antes da descoberta dos microrganismos por Pasteur, e a diminuição de sua utilização se deu pelo uso indiscriminado de antibióticos (NOGAROTO; PENNA, 2006).

A procura pelo bem-estar requer entre outras coisas, um ambiente limpo, seja ele o local onde moramos trabalhamos ou passamos um pequeno período do dia. Para conseguir esse objetivo, a utilização de saneantes, conhecidos como produtos de limpeza, é indispensável. Os desinfetantes, que fazem parte desta categoria e desempenham um papel importante no que se refere a proteção humana. Estes produtos possuem agente bactericida, capazes de eliminar agentes etiológicos. Dessa forma, controlando a contaminação microbiológica dos ambientes (PETILLO, 2002; SENA et al., 2010).

A determinação da eficiência dos desinfetantes é alcançada por meio do desafio deste produto com a microbiota residente e transitória dos locais em que se pretende eliminar ou diminuir o número de microrganismos viáveis, assim extinguindo a possibilidade de desvios de qualidade (PEREIRA, 2005).

No Brasil, a regulamentação dos desinfetantes fica a cargo da Agência Nacional de Vigilância Sanitária (Anvisa), sendo a comprovação da eficácia um requisito fundamental para o seu registro. A utilização desse produto requer cuidados importantes. $O$ consumidor deve atentar-se aos produtos clandestinos, muitas vezes vendidos de porta em porta ou até mesmo em caminhões ou lojas que vendem produtos de limpeza. Na maioria das vezes, 
esses produtos não possuem a substância ativa capaz de eliminar os microrganismos nem passaram por ensaios toxicológicos que comprovem que os mesmos não cause danos, como problemas respiratórios, queimaduras, irritações, entre outros problemas ao indivíduo que utilizar. Além disso, de acordo com o Sistema Nacional de Informações Tóxico-Farmacológicas (Sinitox), a terceira causa mais comum de intoxicação se dá por produtos saneantes, ficando atrás apenas dos medicamentos e animais peçonhentos (INMETRO, 2008).

Por tratar-se de produtos relacionados à proteção da saúde humana, apresentando em sua composição um ou mais agentes bactericidas, é necessário que suas propriedades sejam avaliadas, visando comprovar a sua qualidade, garantindo assim segurança ao consumidor. Diante disso, se torna indispensável a avaliação da rotulagem e de determinados parâmetros físicoquímicos, bem como a comprovação da eficácia antimicrobiana.

Assim, o presente estudo teve como objetivo avaliar parâmetros de qualidade físico-químicos e eficácia microbiológica de produtos domissanitários de abrangência local e nacional.

\section{Materiais e métodos}

Foram analisadas 4 amostras sendo 2 de abrangência nacional e 2 de abrangência local produzidas no Ceará e na Paraíba, identificadas por letras (A e B - Nacional, C e D - Local) prosseguindo os testes de $\mathrm{pH}$, índice de espuma, teste de centrífuga e teste de eficácia antimicrobiana, através do ensaio de difusão em ágar.

\subsection{Análise da rotulagem}

Os rótulos foram avaliados quanto ao cumprimento da RDC14/07 (ANVISA) que determina a obrigatoriedade das seguintes informações: a) Nome e/ou marca do produto; e b) Categoria do produto, indicando o uso principal do produto. O quadro 1 apresenta todos os itens obrigatórios na rotulagem de um produto saneante. 
Quadro 1: Itens Obrigatórios na rotulagem de produtos saneantes com ação antimicrobiana - RDC 14/07

\begin{tabular}{|c|c|}
\hline REF. & ÍTEM \\
\hline 1 & Classificação \\
\hline 2 & $\begin{array}{l}\text { Frases relacionadas com o risco, frases de advertências e } \\
\text { de primeiros socorros indicadas no Anexo IV. }\end{array}$ \\
\hline 3 & Restrições de uso (se for o caso). \\
\hline 4 & $\begin{array}{c}\text { Instruções de uso: no painel principal ou no painel } \\
\text { secundário. }\end{array}$ \\
\hline 5 & $\begin{array}{l}\text { Diluição de uso: se for o caso, deve ser expressa em } \\
\text { porcentagem, relação produto/diluente e seus } \\
\text { equivalentes no Sistema Métrico Decimal. }\end{array}$ \\
\hline 6 & Tempo de contato: segundo o uso proposto. \\
\hline 7 & $\begin{array}{l}\text { Limitações de uso: de acordo com as características da } \\
\text { formulação. }\end{array}$ \\
\hline 8 & $\begin{array}{l}\text { "ANTES DE USAR LEIA AS INSTRUÇÕES DO RÓTULO"; } \\
\text { frase obrigatória no painel principal, em destaque. }\end{array}$ \\
\hline 9 & $\begin{array}{l}\text { Princípios ativos: nomes químicos ou técnicos com suas } \\
\text { respectivas concentrações no painel principal do produto } \\
\text { ou no secundário. }\end{array}$ \\
\hline 10 & Número do registro com a sigla da Autoridade competente. \\
\hline 11 & $\begin{array}{l}\text { A menção ou não no rótulo do produto do nome do } \\
\text { Responsável Técnico no Estado Parte receptor, deverá } \\
\text { respeitar as exigências legais previstas no mencionado } \\
\text { Estado Parte. }\end{array}$ \\
\hline
\end{tabular}

Fonte: Adaptado de Brasil, 2007.

\subsection{Análise físico-química}

\subsubsection{Características organolépticas}

As amostras foram analisadas visualmente quanto aos aspectos, cor, odor e homogeneidade e ausência de qualquer matéria sólida, sujidade, entre outras.

\subsection{2 $\mathrm{pH}$}

A determinação potenciométrica, foi realizada em triplicata utilizando o aparelho peagamêtro PHTEK que mede a diferença de potencial entre dois eletrodos, um deste sensível aos íons hidrogênios e o outro de referência, imersos diretamente na amostra. As amostras foram usadas na sua forma pura (BRASIL, 2010a).

\subsection{3. Índice de espuma}

Colocou-se $0,25 \mathrm{~mL}$ das amostras-teste para $25 \mathrm{~mL}$ de água destilada em uma proveta com capacidade de $100 \mathrm{~mL}$. Esta foi submetida a agitação manual verticalmente, cinco vezes consecutivas. Em seguida, o volume de espuma 
formado $(\mathrm{cm})$ foi medido em tempo zero e novamente no tempo de 5 minutos (SBRT, 2007; FARIA, et al., 2012).

\subsubsection{Teste de centrífuga}

Para a avaliação de estabilidade, amostras foram submetidas durante quinze minutos a quatro mil rotações por minuto (rpm), em centrífuga CentriBio seguida da observação visual de características de instabilidade (BRASIL, 2008).

\subsection{Ensaio de eficácia antimicrobiana}

Para a realização dos testes de comprovação da eficácia antimicrobiana, foi utilizado o método de difusão em ágar.

Utilizaram-se cepas de bactérias Gram-negativas Pseudomonas aeruginosa e Escherichia coli; a bactéria Gram-positiva Staphylococcus aureus e os fungos Candida albicans e Aspergillus niger, com as quais preparou-se suspensões em solução salina $0,9 \%$, resultando na preparação de meios inoculados com cada um os microrganismos testes.

Para a realização do teste, utilizaram-se placas de Petri $(20 \mathrm{~mm} \times 100$ $\mathrm{mm}$ ) e cilindros de aço inoxidável ( $8 \mathrm{~mm} \times 6 \mathrm{~mm} \times 10 \mathrm{~mm}$ ). Todo o material utilizado no ensaio foi previamente esterilizado.

Foi utilizado o meio de cultura Ágar Sabouraud-Dextrose (ASD) para o teste com fungos e Ágar Nutriente as bactérias. Nas placas de Petri foram preparadas as camadas base com $20 \mathrm{~mL}$ de meio estéreo e após a solidificação verteu-se $5 \mathrm{~mL}$ de meio inoculado para a composição da camada semeada seguido da distribuição de 4 cilindros em cada placa (fig.1). Em cada cilindro foi adicionado $200 \mu \mathrm{L}$ das diluições de cada amostra. As placas foram avaliadas em relação a formação e medida dos halos de inibição após o período de incubação (BRASIL, 2010a). 


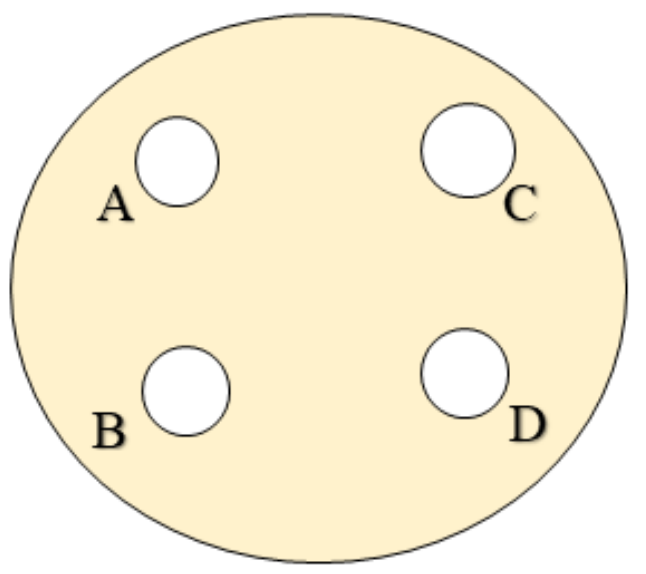

Figura 1: Representação da disposição dos cilindros para o teste de potência dos desinfetantes.

Fonte: Autoria própria (2017)

\subsubsection{Preparo do Inóculo e das amostras}

Os microrganismos foram repicados em meio inclinado 24 horas antes do ensaio, os fungos foram repicados em tubo com ASD a $2 \%$ inclinado e as bactérias em tubo com ágar nutriente a $2 \%$ e foram mantidos à temperatura de $25^{\circ} \mathrm{C}$ e $37^{\circ} \mathrm{C}$, respectivamente, em estufa bacteriológica. $\mathrm{O}$ inóculo foi preparado a partir da suspensão em solução de cloreto de sódio $0,9 \%$ dos microrganismos de interesse, separadamente e padronizados em espectofotômetro visível digital microprocessado em comprimento de onda de $580 \mathrm{~nm}$ até obtenção de uma suspensão a $25 \% \pm 2 \%$ de transmitância.

As amostras foram diluídas de acordo com a indicação rotulada de uso de cada desinfetante para a aplicação.

\section{Resultados e discussão}

\subsection{Rotulagem e embalagem}

Apenas o produto " $\mathrm{B}$ " apresentou todos os itens obrigatórios na rotulagem de produtos. As amostras "A", "C" e "D" apresentavam a classificação de limpador perfumado, mas eram vendidos como desinfetantes de uso geral. O produto "A" não apresentou em seu rótulo o tempo de contato, as limitações de uso e a frase obrigatória "Antes de usar leia as instruções no rótulo".

Os desinfetantes locais não apresentaram registro na ANVISA, além disso, não possuíam a limitação de uso e a frase obrigatória "Antes de usar leia as instruções no rótulo". O desinfetante "C" não continha o nome do princípio 
ativo, apesar de no rótulo afirmar que havia agente bactericida e a diluição de uso encontrava-se errada, já que o rótulo comparava $300 \mathrm{~mL}$ do produto à 3 colheres de sopa, quando na verdade as três colheres correspondem a $45 \mathrm{ml}$, aproximadamente.

De acordo com a análise da composição rotulada (Quadro 02), apenas a amostra B apresenta ativo antimicrobiano, o o-benzil p-clorofenol, os demais produtos são compostos por substâncias com função detergente (tensoativos), no entanto além da amostra $B$, os produtos $C$ e $D$ também declaram atividade antimicrobiana, mas como "Limpador Perfumado", termo não encontrado na classificação dos tipos de saneantes da ANVISA.

Quadro 2: Composição rotulada das amostras analisadas

\begin{tabular}{cccc}
\hline Marca & Princípio Ativo & Função Química & Referência \\
\hline A & $\begin{array}{c}\text { Alqui benzeno sulfato de } \\
\text { sódio, laurel éter sulfato de } \\
\text { sódio, lauramina óxida }\end{array}$ & Tensoativo aniônico & Oliveira, 2008 \\
B & O-benzil p-clorofenol & Derivados fenólicos & Oliveira, 2008 \\
C & Não especificado pelo & - & - \\
& fabricante & Tensoativo não & Pinheiro, 2014 \\
D & Nonil fenol etoxilado & iônico & \\
\hline
\end{tabular}

Fonte: Dados da pesquisa (2017)

Segundo Pinto, Kaneko e Pinto (2015), as cargas dos íons presentes nesses compostos podem causar repelência aos microrganismos, levando-os à dissociação da superfície, auxiliando na posterior remoção ou posterior destruição pela aplicação de um desinfetante. Além disso, muitos detergentes possuem aditivos químicos em sua formulação que podem apresentar características desinfetantes. Por outro lado, a presença de surfactantes, como os polissorbatos, nas formulações, neutraliza diversos tipos de desinfetantes.

\subsection{Características organolépticas}

Uma das evidências de instabilidade físico-química de formulações é a alteração nas características organolépticas do produto relacionado à coloração e odor (CUNHA; SILVA; CHORILLI, 2009). Utilizou-se de análise 
macroscópica para avaliar as formulações, tendo como princípio que a avaliação visual (Figura 2) é uma maneira clara para se observar separação de fases ou instabilidade, capaz de fornecer informações significativas.



Figura 2: Aspecto visual das amostras de produtos saneantes domissanitários analisados

Fonte: Arquivos da pesquisa (2017).

Neste quesito, todas as marcas avaliadas mostraram-se dentro dos padrões, apresentando aparência homogênea e estável. Por não haver uma regulamentação que padronize a fabricação desses produtos, cada fabricante possui o direito de atribuir o aspecto que desejar a sua formulação, obtendo assim uma característica própria da sua marca, desde que não apresentem indicativos de perda de estabilidade física.

\section{$3.3 \mathrm{pH}$}

A variação no valor de $\mathrm{pH}$, fora do intervalo declarado pelo fabricante, pode comprometer a estabilidade do produto e interferir na ação desinfetante (INMETRO, 2008).

De acordo com a Resolução n59/2010, a amostra A apresentou pH $(11,53)$ característico de produto de risco 2 , enquanto que as amostras $(B, C$ e D) são classificadas como de risco 1 (faixa de pH entre 2 e 11,5), conforme apresentado na tabela 1 (BRASIL, 2010b).

Tabela 1: Valores de pH das amostras analisadas

\begin{tabular}{ccccc}
\hline Desinfetantes & A (Nacional) & B (Nacional) & C (Local) & D (Local) \\
\hline pH & 11,53 & 8,25 & 7,61 & 7,8 \\
\hline
\end{tabular}


$\mathrm{O}$ valor de $\mathrm{pH}$ para ter efeito na ação antimicrobiana irá depender do desinfetante, dos microrganismos e do item submetido a desinfecção. Deve ser determinado durante o desenvolvimento da formulação de acordo com a composição, de forma que respeite a faixa estabelecida pela ANVISA (NOGAROTO; PENNA, 2006; LIMA, 2016).

Diferentes microrganismos sobrevivem em faixas de $\mathrm{pH}$ diversas, mas em geral, a maioria cresce melhor em ambientes com faixa de pH entre 6,5 e 8,5. Poucas bactérias são capazes de crescer em pH ácido $(4,0)$. Ao contrário, os fungos são capazes de tolerar condições mais ácidas, com valores ótimos de crescimento entre $\mathrm{pH} 5$ e 6 . A alcalinidade também inibe o crescimento microbiano, no entanto, raramente é utilizada na inibição do crescimento (TORTORA, FUNKE, CASE, 2017)

$\mathrm{O} \mathrm{pH}$ das amostras $\mathrm{B}, \mathrm{C}$ e $\mathrm{D}$, encontra-se na faixa de crescimento ótimo para a maioria dos microrganismos, logo, não deve influenciar na atividade antimicrobiana dos produtos analisados.

\section{4 Índice de espuma}

Todas as amostras analisadas apresentaram pouca ou nenhuma formação de espuma, com valores variando de 0 a $3 \mathrm{~mm}$ no tempo zero e de 0 a $2 \mathrm{~mm}$ após 5 , conforme apresentado na tabela 2.

Tabela 2: Valores da altura da espuma obtidos no teste

\begin{tabular}{ccc}
\hline \multirow{2}{*}{ Índice de espuma } & \multicolumn{2}{c}{ Tempo } \\
\cline { 2 - 3 } A (Nacional) & $\mathbf{0}$ & $\mathbf{5}$ \\
B (Nacional) & $0 \mathrm{~mm}$ & $2 \mathrm{~mm}$ \\
C (Local) & $0,2 \mathrm{~mm}$ & $0 \mathrm{~mm}$ \\
D (Local) & $0,7 \mathrm{~mm}$ & $0,4 \mathrm{~mm}$ \\
\hline
\end{tabular}

Fonte: Dados da pesquisa, 2017

A espuma como a viscosidade não tem influência no poder de limpeza, porém, comercialmente é importante, pois a publicidade desloca o foco de atenção do consumidor associando o processo de limpeza com a formação da espuma. No entanto, em desinfetantes a não produção da espuma se torna mais vantajosa, pois não é algo que se espera do produto (CORRÊA, 2005; SBRT, 2007). 


\subsection{Teste de centrífuga}

O teste de centrífuga revelou que nenhum dos produtos avaliados, apresentou qualquer alteração, como separação de fases, ou precipitação. Todos se mantiveram estáveis durante o teste. Não revelando problemas com a estabilidade das formulações nas condições experimentais empregadas.

Nesse teste, a centrifugação produz estresse na amostra, simulando um aumento na força da gravidade, aumentando a mobilidade das partículas e antecipando possíveis instabilidades. Nesse teste foi utilizado centrífuga CentriBio as quais as amostras foram submetidas durante quinze minutos à quatro mil rotações por minuto (rpm), em seguida, foi feito a observação visual (BRASIL, 2008).

Resultados semelhantes foram encontrados por Garcia et al., (2009) e Bezerra et al., (2016), em avaliação de formulações de sabonetes líquidos e por Souza e Nóbrega (2018) em xampus de cetoconazol.

\subsection{Ensaio de potência microbiológica}

Os microrganismos utilizados no teste foram escolhidos devido serem os mais conhecidos por causar doenças em seres humanos e representarem um amplo espectro contemplando bactérias Gram positivas e Gram negativas e fungos filamentoso e leveduriforme.

O crescimento dos microrganismos foi homogêneo e os halos de inibição formados mostraram-se bem definidos (Figura 03). 


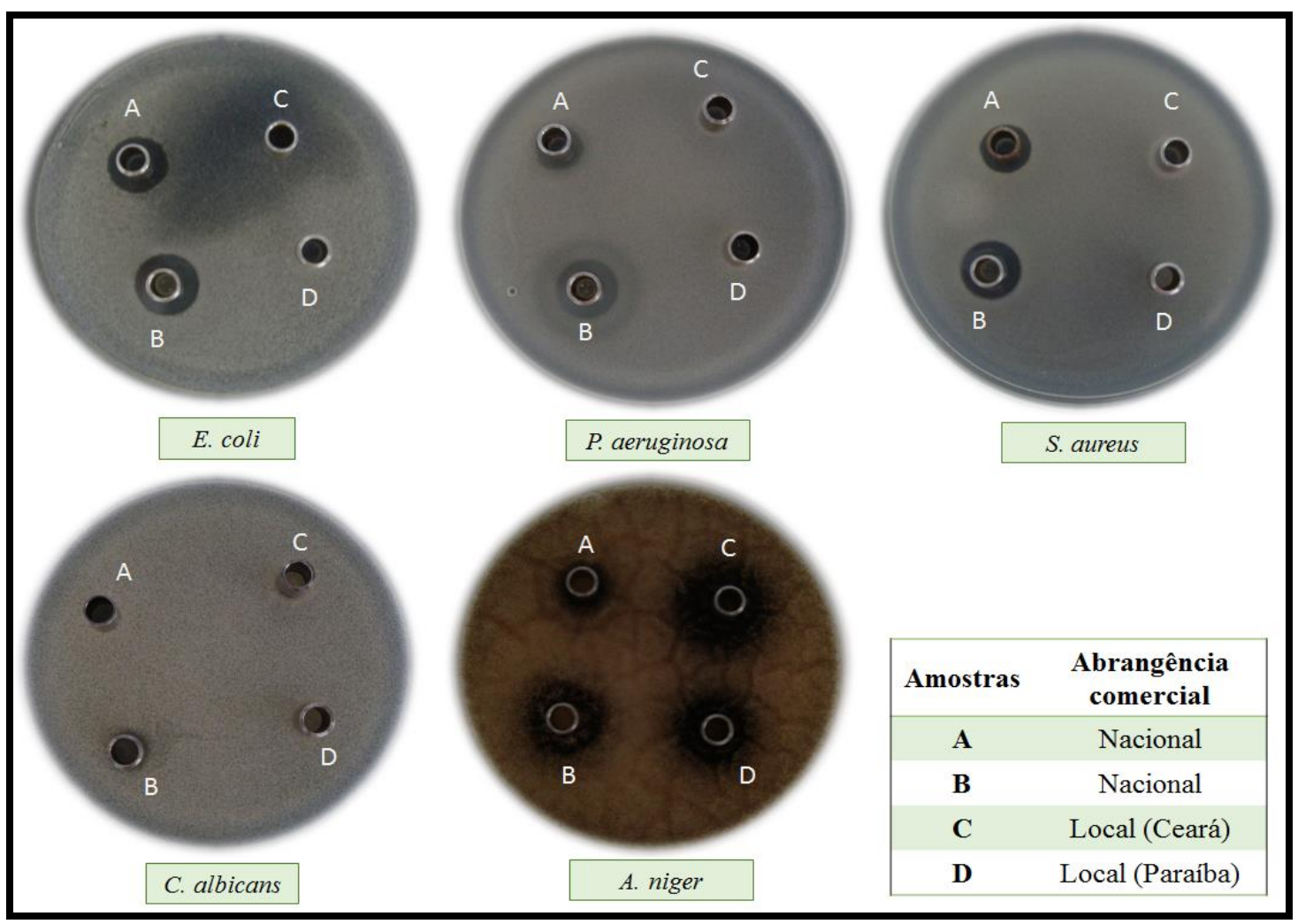

Figura 3: Atividade antimicrobiana dos produtos analisados nas diluições de uso recomendadas sobre os microrganismos testes pelo método de difusão em ágar

Fonte: Arquivos da pesquisa (2017)

No presente estudo, nenhum dos desinfetantes se mostrou capaz de inibir o crescimento dos fungos e de $P$. aeruginosa, evidenciado pela ausência de formação de halos de inibição em todas as placas (Figura 3).

Os fungos são seres difundidos no meio ambiente, em vegetais, ar atmosférico, solo e água e, embora sejam estimados em 250 mil espécies, foram descritos menos de 150 espécies patógenas aos seres humanos. As leveduras são fungos que tem a capacidade de colonizar o homem e animais e, diante da perda do equilíbrio parasita-hospedeiro, podem causar diversos quadros infecciosos com formas clínicas localizadas ou disseminadas. No entanto, fungos filamentosos, ou bolores, normalmente, não fazem parte da microbiota animal e, portanto, o homem não é um reservatório importante para esse grupo de fungos. As portas de entrada no hospedeiro são as vias aéreas superiores ou quebra na barreira epidérmica após traumatismos com objetos perfuro cortantes (HONORATO, 2009).

Em um estudo realizado por Redü (2014), a Candida albicans mostrou-se sensível ao digluconato de clorexidina nas concentrações testadas. 
Em um estudo realizado por Xavier et al., (2008), foi testado os desinfetantes contendo como princípios ativos o iodóforo, digluconato de clorexidina e cloreto de benzalcônio frente aos fungos Aspergillus fumigatus, Aspergillus niger, Aspergillus flavus e Aspergillus terreus. Todos os isolados de Aspergillus spp. se mostraram resistentes ao iodóforo nas diluições testadas. $\mathrm{O}$ cloreto de benzalcônio mostrou atividade "in vitro" no controle das quatro espécies de Aspergillus, com exceção de uma amostra de A. fumigatus, que apresentou resistência a este agente químico mesmo em uma concentração duas vezes a recomendada. E, o digluconato de clorexidina apresentou eficácia frente a todos os isolados de A. fumigatus, $A$. niger e $A$. flavus, no entanto, a amostra de $A$. terreus foi considerada resistente a todas as diluições testadas.

Em um estudo realizado por Honorato (2009) com o intuito de verificar a presença de fungos em uma U.T.I. antes e depois da limpeza com desinfetantes, observou uma redução de $18 \%$ de colônias de fungos.

Em outro estudo realizado por Mattei et al., (2013) verificou que o derivado de cloro-fenol foi eficaz em todos os isolados de fungos utilizados no teste, com concentração inibitória mínima e concentração fungicida mínima menor que a concentração indicada pelo fabricante.

No presente estudo, ressalta-se a ineficácia de todas as amostras contra os fungos testados, apesar do marketing apresentado no rótulo da amostra A "elimina 99,9\% dos germes, fungos e leveduras".

Com relação as bactérias, os diferentes tipos reagem de modo distinto à coloração de Gram porque estas apresentam diferenças na estrutura de suas paredes celulares. Entre as diferenças, as bactérias Gram-positivas possuem uma parede de peptideoglicano mais espessa, já a bactéria Gram-negativa apresenta uma camada de lipopolissacarídeo (TORTORA; FUNKE; CASE, 2012). Além disso, as bactérias, como todos os seres vivos, exibem mecanismos biológicos que as permitem se adequar a diversas pressões ambientais. A resistência adquirida aos anti-sépticos e desinfetantes surge por uma propriedade natural de um organismo, ou surge por mutação ou por aquisição de plasmídeos ou transposons. (GONZÁLEZ, 2011).

A bactéria $P$. aeruginosa é um bastonete Gram negativo ubíquo, temabolicamente versátil, raramente associado a patologias em indivíduos 
sadios; entretanto, atualmente é considerada como uma das principais causas de uma ampla gama de infecções oportunistas graves em pacientes com condições médica subjacentes, principalmente relacionada a queimaduras, fibrose cística, bronquite crônica e infecções do trato urinário (TORRES et al., 2006; GELLATLY; HANCOCK, 2013). Demonstra susceptibilidade diminuída à maioria dos antibióticos devido à baixa permeabilidade da membrana externa acoplada a mecanismos adaptativos e pode prontamente alcançar resistência clínica (BREIDENSTEIN; DE LA FUENTE-NÚÑEZ; HANCOCK, 2011). A propensão do organismo a crescer in vivo como biofilme tolerante a antimicrobianos e a ocorrência de cepas hipermutadoras produzem mutantes antimicrobianos resistentes em maior frequência. (POOLE, 2011)

O Nonilfenol etoxilado é um surfactante não iônico. São assim caracterizados por possuírem grupos hidrofílicos sem cargas ligados à cadeia graxa. Sua solubilidade em água é devida à hidratação dos grupos hidrófilos (OLIVEIRA, 2008; PINHEIRO, 2014).

Apenas os desinfetantes "A" e "B" se mostraram eficientes na inibição de S. aureus, apresentando valores médios de halos de inibição de 10,2 \pm 0,45 $\mathrm{mm}$ e $12,7 \pm 0,45 \mathrm{~mm}$, e $E$. coli, com halos de inibição de 12,9 $\pm 1,02 \mathrm{~mm}$ e 14,3 \pm 0,67 mm (Tabela 3).

Tabela 3. Halos de inibição em $\mathrm{mm}$ (Média \pm DP) das amostras analisadas nas diluições recomendadas de uso sobre os microrganismos testes pelo método de difusão em ágar $(n=5)$

Microrganismo

Amostra

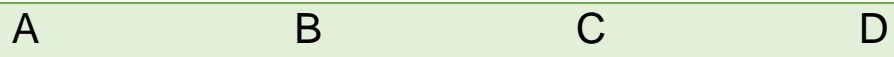

S. aureus $\quad 10,2 \pm 0,45 \quad 12,7 \pm 0,45$

E. coli $12,9 \pm 1,02 \quad 14,3 \pm 0,67$

P. aeruginosa

C. albicans

A. niger

Fonte: Dados da pesquisa, 2017.

Os dados mostram coeficientes de variação entre 10,2 e 14,3\%, encontrando-se dentro dos limites aceitáveis para a confiabilidade dos ensaios realizados. De acordo com a $\mathrm{RE}$ 899/03, o valor máximo aceitável deve ser 
definido de acordo com a metodologia empregada, a concentração do analito na amostra, o tipo de matriz e a finalidade do método, não permitindo valores superiores a 15\% quando se tratar de métodos biológicos (BRASIL, 2003). Portanto, o ensaio utilizado apresenta precisão adequada ao doseamento microbiológico para avaliar eficácia antimicrobiana de desinfetantes frente ao crescimento de E. coli e S. aureus.

Em um estudo realizado por Oliveira (2008), a contagem de unidades formadora de colônias para Salmonella choleraesuis após o teste com base alcoólica com $1,5 \%$ de alquil benzeno sulfato de sódio apresentou efeito antimicrobiano nulo. Por outro lado, apresentou atividade contra Staphylococcus aureus com efeito microbicida. Os resultados obtidos no presente estudo estão de acordo com a literatura, atribuindo aos ativos aniônicos uma fraca atividade antimicrobiana para as bactérias Gram-negativas e relevante atividade antimicrobiana para as bactérias Gram-positivas. Estes resultados podem ser explicados pelo fato que tensoativos mais hidrofóbicos possam ter atuação antimicrobiana secundária, mais afetiva em relação aos tensoativos mais solúveis, como os tensoativos não-iônicos.

Os derivados fenólicos atuam alterando a permeabilidade da membrana celular e induzindo uma progressiva perda de constituintes intracelulares. Em altas concentrações ocorre coagulação intracelular e em baixas concentrações, vai ocorrer a adsorção do princípio ativo na membrana da célula e os danos relacionados a esta adsorção são reversíveis, o que confere caráter bacteriostático (OLIVEIRA, 2008; GONZÁLEZ, 2011).

O objetivo dos testes de eficácia de desempenho é demonstrar a habilidade do desinfetante para provocar letalidade dos organismos de interesse (PINTO; KANEKO; PINTO, 2015)

O ensaio de eficácia antimicrobiana desse estudo mostrou que não houve inibição dos microrganismos pelos desinfetantes de comercialização local (C e D) e que os desinfetantes de abrangência nacional ( $A$ e B) não inibiram todos os microrganismos testados, esse resultado pode indicar ausência do princípio ativo nos produtos locais ou que eles apresentam uma concentração insuficiente do ativo em todos os desinfetantes, dessa forma não desempenhando a função esperada. 
Vale ressaltar que as amostras de desinfetantes de comercialização local, não apresentando registro/notificação junto ao órgão de fiscalização, ANVISA, são categorizadas como clandestinos. Para fins de registro/notificação é exigida a apresentação de resultado/laudo de análise química e de eficácia microbiológica do produto de acordo com o uso proposto (BRASIL, 2007).

\section{Conclusão}

Os dados de rotulagem revelaram que apenas um dos quatros desinfetantes analisados encontrava-se de acordo com a regulamentação vigente.

Com relação aos parâmetros físico-químicos, todas as amostras apresentaram índice de espuma e teste de centrífuga adequada, contudo a amostra $\mathrm{A}$, apresentou $\mathrm{pH}$ característico de risco 2 e as demais amostras, risco 1.

Os saneantes locais ( $C$ e $D$ ) foram ineficazes contra todos os microrganismos testados. Os produtos nacionais (A e B) apresentaram eficácia apenas contra dois (E. coli e $S$. aureus) dos cinco microrganismos teste. Dessa forma, nenhuma das amostras foi capaz de inibir o crescimento fúngico.

\section{Referências}

BEZERRA, Priscilla Xavier et al. Avaliação da Rotulagem e Parâmetros de Qualidade de Sabonetes Íntimos. Revista Brasileira de Ciências da Saúde, v. 20, n. 1, p. 51-60, 2016. Disponível em:

https://www.google.com.br/search?ei=Zf77W u6KsGcwgSmalXYDQ\&q=BEZERRA\%2 C+P.+X.+et+al.+Avalia\%C3\%A7\%C3\%A30+da+Rotulagem+e+Par\%C3\%A2metros+d e+Qualidade+de+Sabonetes+\%C3\%8Dntimos.Revista+Brasileira+de+Ci\%C3\%AAncia $\mathrm{s}+\mathrm{da}+\mathrm{Sa} \% \mathrm{C} 3 \%$ BAde $\% 2 \mathrm{C}+\mathrm{v} .+20 \% 2 \mathrm{C}+\mathrm{n} .+1 \% 2 \mathrm{C}+$ p. $+51-$ 60\%2C+2016.\&oq=BEZERRA\%2C+P.+X.+et+al.+Avalia\%C3\%A7\%C3\%A3o+da+Rotu lagem+e+Par\%C3\%A2metros+de+Qualidade+de+Sabonetes+\%C3\%8Dntimos. Revist a+Brasileira+de+Ci\%C3\%AAncias+da+Sa\%C3\%BAde\%2C+v.+20\%2C+n.+1\%2C+p.+ 51-60\%2C+2016.\&gs l=psy-

ab.3..35i39l6.16084.16609..16916...1.0..0.0.0......0...1j2..gws-wiz....6.8FmZ90QjGvE Acesso em: 13 jul 2018.

BRASIL. Farmacopeia brasileira. $5^{\underline{a}}$ ed. Brasília: ANVISA, 2010a. 
BRASIL. Guia de Controle de Qualidade de Produtos Cosméticos. $2^{\underline{a}}$ ed. Brasília: ANVISA, 2008.

BRASIL. Resolução - RE no 899, de 29 de maio de 2003. 2003. Disponível em:< http://redsang.ial.sp.gov.br/site/docs leis/vm/vm1.pdf >. Acesso em: 14 jul. 2018.

BRASIL. Resolução RDC n 14, de 28 de fevereiro de 2007. 2007. Disponível em: < http://www.cevs.rs.gov.br/upload/arquivos/201611/08140937-rdc-14-2007.pdf $>$. Acesso em: 14 jul. 2018.

BRASIL. Resolução RDC n 59, de 17 de dezembro de 2010. 2010b. Dispõe sobre os procedimentos e requisitos técnicos para a notificação e o registro de produtos saneantes e dá outras providências. Disponível em:< http://portal.anvisa.gov.br/documents/33880/2568070/res0059 1712 2010.pdf/194eb be3-15ea-4817-b472-f73cc76441c2 > . Acesso em: 14 jul. 2018.

BREIDENSTEIN, Elena B. M; DE LA FUENTE-NÚÑEZ, César; HANCOCK, Robert E. W. Pseudomonas aeruginosa: all roads lead to resistance. Trends in microbiology, $v$. 19, n. 8, p. 419-426, 2011.

CORRÊA, Lilia Modesto Leal. Saneantes domissanitários e saúde: Um estudo sobre a exposição de empregadas domésticas. 2005. 94 f. Dissertação (Mestrado em Saúde Coletiva) - Universidade Federal do Rio de Janeiro, Rio de Janeiro, 2005.

CUNHA, Aline Roberta; SILVA, Rafael Silveira; CHORILLI, Marlus. Desenvolvimento e avaliação da estabilidade física de formulações de xampu anticaspa acrescidas ou não de extratos aquosos de hipérico, funcho e gengibre. Revista Brasileira de Farmácia, v.90, n.3, p.190-195, 2009. Disponível em: http://rbfarma.org.br/files/pag 190a195 estabilidade formulacoes 232.pdf Acesso em: 13 jul 2018.

FARIA, Andreia Bonuzzi et al. Desenvolvimento e avaliação de produtos cosméticos para a higiene capilar contendo tensoativos "não-sulfatados". Revista Ciências Farmacêuticas Básica e Aplicada, v. 33, n. 4, p. 521-527, 2012. Disponível em: https://web.b.ebscohost.com/abstract?direct=true\&profile=ehost\&scope=site\&authtype $=$ crawler\&jrnl=18084532\&AN=89291052\&h=k4TvAlwzIIPh3vT4IXHJwcEjxvgZ9Ete6\%2 b8KmJcCkbbl8cn9NZc1PPlj2uBr5UMqlwSQ103B6s\%2fed\%2b57diiKPg\%3d\%3d\&crl= 
c\&resultNs=AdminWebAuth\&resultLocal=ErrCrlNotAuth\&crlhashurl=login .aspx\%3fdire ct\%3dtrue\%26profile\%3dehost\%26scope\%3dsite\%26authtype\%3dcrawler\%26jrnl\%3d 18084532\%26AN\%3d89291052 Acesso em: 13 jul 2018.

GARCIA, Carla Cristina et al. Desenvolvimento e avaliação da estabilidade físicoquímica de formulações de sabonete líquido íntimo acrescidas de óleo de melaleuca. Rev. Bras. Farm, v. 90, n. 3, p. 236-240, 2009. Disponível em: http://www.rbfarma.org.br/files/pag $236 a 240$ sabonete liquido intimo 253.pdf Acesso em: 13 jul 2018.

GELLATLY, Shaan L.; HANCOCK, Robert E. W. Pseudomonas aeruginosa: new insights into pathogenesis and host defenses. Pathogens and disease, v. 67, n. 3, p. 159-173, 2013. Disponível em: https://www.ncbi.nlm.nih.gov/pubmed/23620179 Acesso em: 13 jul 2018.

GONZÁLEZ, Nestor Hugo. Capacidade de inativação de desinfetantes sobre microorganismos isolados de superfícies físicas em áreas críticas de um hospital veterinário de ensino. 2011. 64 f. Dissertação (Mestrado em Ciências Veterinárias) - Universidade Federal do Rio Grande do Sul, Porto Alegre, 2011.

HONORATO, Glauber Menoni. Verificação de fungos anemófilos na U.T.I. do Hospital Santa Lucinda (Sorocaba/SP), antes e depois de sua limpeza. Revista Eletrônica de Biologia, v.2, n.3, p.19-31, $2009 . \quad$ Disponível em: https://revistas.pucsp.br/index.php/reb/article/view/26 Acesso em: 26 nov 2018.

INMETRO. INSTITUTO NACIONAL DE METROLOGIA, QUALIDADE E TECNOLOGIA. Programa de análise de produtos: relatório sobre análise em desinfetantes de uso geral. 2008. Disponível em:< http://www.inmetro.gov.br/consumidor/produtos/desinfetante2.pdf>. Acesso em: 14 jul. 2018.

LIMA, Heloísa Didier. Controle de qualidade em indústria de saneantes domissanitários. Natal. Relatório (Estágio supervisionado) - Universidade Federal do Rio Grande do Norte, 2016.

MATTEI, Antonella Souza et al. Efeito antifúngico de agentes químicos sobre leveduras com potencial patogênico isoladas de ambiente hospitalar veterinário. 
Brazilian Journal Veterinary Research and Animal Science, v. 50, n. 4, p. 294-299, 2013. Disponível em: http://www.revistas.usp.br/bjvras/article/view/74686 Acesso em 13 jul 2018.

NOGAROTO, Sérgio Luis; PENNA, Thereza Christina Vessoni. Desinfecção e Esterilização. 1․ ed. São Paulo: Atheneu, 2006.

PEREIRA, Milca Severino et al. A infecção hospitalar e suas implicações para o cuidar da enfermagem. Revista Texto e Contexto Enfermagem, v. 14, n.2, p.250-257, 2005. Disponível em: http://www.scielo.br/pdf/tce/v14n2/a13v14n2.pdf Acesso em 13 jul 2018.

PETILLO, Vera Lúcia Siqueira; PHILIPPI JR, Arlindo. A prevenção da poluição química de interiores e o uso de produtos de limpeza. In: CONGRESO INTERAMERICANO DE INGENIERÍA SANITARIA Y AMBIENTAL, 18., 2002, Cancún. Anais eletrônicos... Cancún: $\quad$ AIDIS, $2002 . \quad$ Disponível em:< http://www.bvsde.paho.org/bvsaidis/mexico26/vi-018.pdf>. Acesso em: 13 jul. 2002.

PINHEIRO, Aline Martins. Pós-tratamento de efluentes saneante domissanitário por ozonização convencional e catalítica. 2014. 175 f. Dissertação (Mestrado em Engenharia Civil) - Universidade Federal de Uberlândia, Uberlândia, 2014.

PINTO, Terezinha de Jesus Andreoli; KANEKO, Telma Mary; PINTO, Antônio F. Controle biológico de qualidade de produtos farmacêuticos, correlatos e cosméticos. São Paulo: Manole, 2015.

POOLE, Keith. Pseudomonas aeruginosa: resistance to the max. Frontiers in microbiology, $\quad$ v. $2, \quad$ p. $65,2011 . \quad$ Disponível em: https://www.ncbi.nlm.nih.gov/pmc/articles/PMC3128976/ Acesso em: 13 jul 2018.

REDÜ, Josiara Furtado Mendes. Atividade biocida de desinfetantes e fitoquímicos frente a fungos isolados de animais silvestres mantidos em centro de recuperação. 2014. 94 f. Dissertação (Mestrado em Ciências Veterinárias) Universidade Federal do Rio Grande do Sul, Porto Alegre, 2014. 
SBRT. SERVIÇO BRASILEIRO DE RESPOSTAS TÉCNICAS. Dossiê Técnico Detergentes Doméstico, Instituto de Tecnologia do Paraná. 2007. Disponível em: < respostatecnica.org.br/dossie-tecnico/downloadsDT/Mjg>. Acesso em: 14 jul. 2018.

SENA, L. O. et al. Uma avaliação sobre a eficácia dos desinfetantes de uso geral comercializados em Fortaleza-CE. In: CONGRESSO BRASILEIRO DE QUÍMICA, 50., 2010, Cuiabá. Anais eletrônicos... Cuiabá: CBQ, 2010. Disponível em:< http://www.abq.org.br/cbq/2010/trabalhos/4/4-389-8.htm>. Acesso em: 13 jul. 2018.

SOUZA, Júlia Beatriz Pereira; NÓBREGA, Renatha Sousa. Avaliação de parâmetros físico-químicos e eficácia de formulações comerciais de xampus de cetoconazol. Revista Saúde \& Ciência Online, v. 7, n. 1, p. 45-64, 2018. Disponível em: http://www.ufcg.edu.br/revistasaudeeciencia/index.php/RSC-UFCG/article/view/399 Acesso em: 13 jul. 2018.

TORRES, Júlio César Nogueira et al. Cepas de Pseudomonas spp. produtoras de metalo- betalactamase isoladas no Hospital Geral de Fortaleza. J Bras Patol Med Lab, v.42, n.5, p.313-319, 2006. Disponível em: http://www.scielo.br/pdf/ibpml/v42n5/a03v42n5.pdf Acesso em: 13 jul 2018.

TORTORA, Gerard J.; FUNKE, Berdell R.; CASE, Christine L. Microbiologia. Porto Alegre: Artmed, 2017.

XAVIER, Melissa Orzechowski et al. Eficácia da clorexidina-cetrimida na desinfecção ambiental contra Aspergillus spp. Arquivos brasileiros de medicina veterinária e zootecnia, v.60, n.4, p.873-877, $2008 . \quad$ Disponível em: https://www.researchgate.net/publication/250044230 Eficacia da clorexidinacetrimida na desinfeccao ambiental contra Aspergillus spp Acesso em: 13 jul 2018. 